\title{
Glossopharyngeal Nerve
}

National Cancer Institute

\section{Source}

National Cancer Institute. Glossopharyngeal Nerve. NCI Thesaurus. Code C12723.

The ninth cranial nerve. It originates in the brainstem and passes through the jugular foramen. It has motor and sensory functions that relate to the tongue, pharynx and middle ear. 